\title{
The SaaS Payoff: Measuring the Business Value of Provisioning Software-as-a-Service Technologies
}

\author{
Trevor Clohessy, Thomas Acton, and Lorraine Morgan
}

\begin{abstract}
Creating and capturing value with new digital technologies such as cloud computing is often fraught with complexity and ambiguity for incumbent information technology (IT) firms. Using the business model concept as a lens, the objective of this chapter is to address a current gap in our knowledge about the impact of Software-as-a-Service (SaaS) on incumbent IT supply-side organisations. The empirical findings from a cross-case study analysis of two incumbent IT service providers lead to a number of in-depth insights that are discussed in this paper. The study
\end{abstract}

\footnotetext{
T. Clohessy $(\bowtie)$

Department of Enterprise and Technology, Galway-Mayo Institute of

Technology, Galway, Ireland

e-mail: trevor.clohessy@gmit.ie

T. Acton • L. Morgan

Business Information Systems Department, J.E. Cairnes School of Business \& Economics, National University of Ireland, Galway, Ireland

(C) The Author(s) 2020

T. Lynn et al. (eds.), Measuring the Business Value of Cloud

Computing, Palgrave Studies in Digital Business \& Enabling

Technologies, https://doi.org/10.1007/978-3-030-43198-3_3
} 
identifies six tangible business model payoffs that have resulted from provisioning SaaS technologies. Subsequently, this paper lays the foundation for contributing to understanding how SaaS technologies can influence business models.

Keywords Cloud computing $\bullet$ Software-as-a-Service $($ SaaS) $\bullet$ Business model • Payoffs

\subsection{INTRODUCTION}

It is treacherous on a tightrope to change your focus point and suddenly look down. Philip Pettit (The Walk 2015)

This above quote rings no truer than in the current digital technological arena which is characterised by rapid fluctuation and turbulence-a fluid landscape where a multitude of incumbent information technology (IT) organisations are having to change their digital focus and "look down" and embrace emerging digital technological advancements. Digital transformation is concerned with the changes digital technologies can bring about in an organisation's business model and the subsequent changes in products, organisational structures and the automation of processes (Clohessy et al. 2017; Benlian et al. 2016; Hess et al. 2016). The business model concept has been used extensively to examine how digital technologies transform organisational abilities to create and capture value (e.g. the internet, e-commerce platforms, mobile applications, Big Data, analytics, and so on). Driving factors such as the emerging knowledge economy, the restructuring of global financial services, increased outsourcing of business processes and information systems, rapid advancements in digital technologies and the repeated failure of organisations to capitalise on the capabilities afforded by these technologies have catapulted the business model concept back into the public arena (Peters et al. 2015).

In the past decade corporate investments in cloud computing, specifically Software-as-a-Service (SaaS), has increased and become a substantial component of business. Examples of personal use SaaS include, for example, Gmail, Skype, and Dropbox. Salesforce customer relationship management (CRM), SAP Analytics Cloud, and Oracle Enterprise Resource Planning Cloud are examples of business-centric SaaS. Often mentioned benefits include the reduced need for up-front investments in IT 
infrastructure, IT software and IT skills, reduced costs and enhanced flexibility (Guo and Ma 2018). SaaS accounts for the majority of the entire cloud market and it is forecast to reach $\$ 117.1$ billion in revenues by 2021 with an annual growth rate of 16 percent (Gartner 2018). Using the business model as an anchor, this chapter provides new insights into the business model payoffs incumbent IT service providers have been able to leverage as a result provisioning SaaS technologies. Such insights can pave the path for establishing significant theoretical contributions for understanding underlying mechanisms of business model success with regards to SaaS. Our study was guided by the following question:

What business model payoffs manifest for incumbent IT service providers because of provisioning Software-as-a Service technologies?

The remainder of the chapter is structured as follows. In Sect. 3.2, we first provide a rationale for the study and provide an overview of the business model concept. Section 3.3 describes the case study methodology used to address the question above. Section 3.4 discusses the results of the case studies analysed. Finally, the paper concludes with an outline of the study's limitations and the broader study implications where we outline how this research extends extant theoretical and practical contributions.

\subsection{STUdy BACKGROUND}

\subsubsection{SaaS Provision}

There has been an emergent body of research focused on investigating the impact of SaaS on organisational business models. While the majority of this research has been carried out from an adoption perspective, there is a dearth of research which has also explored the impact from an IT supplyside perspective. Thus, the manner with which these organisations are attempting to unleash the digital transformative potential of SaaS through their business models is an area which merits further scrutiny (Benlian et al. 2016; Hess et al. 2016). For instance, there is anecdotal evidence to suggest that incumbent IT service providers are experiencing substantial difficulties in their endeavours to leverage the business model payoffs of provisioning SaaS. This is evidenced by IT stalwarts such as Dell, Intel, IBM and Hewlett Packard (HP) whose struggles pertaining to how to best leverage the payoffs have been well documented. 


\subsubsection{Bounding the Business Model Concept}

It has been argued that the utilisation of the business model concept as an anchor for the identification of the impact of new technologies on organisations is a fairly novel endeavour; it also remains an area which is under researched (Díaz-Díaz et al. 2017). In light of the comprehensive digitisation of enterprises at large, this seems all the more surprising. Business models not only serve as instruments for digital strategic planning but are also used for developing new and existing business activities (Van Kerkhoff et al. 2014). While the single components of extant business model frameworks vary extensively in the literature (Wirtz et al. 2016), they do converge to four overarching dimensions (e.g. value proposition, value co-creation, value delivery and value capture) which can be used to analyse, describe and classify the constituent parts of business models (Peters et al. 2015). In order to address our research questions, we used the Service, Technology, Organisation and Finance (STOF) business model framework (Bouwman et al. 2008) which typifies these four overarching dimensions (Table 3.1). The STOF framework describes how a network of cooperating organisations create and capture value from new digital services across four core business model domains (service, technological, organisational and financial).

The service domain is directly related to the value that is derived by the provider and customer from the service offering. The service offering must be considered better and deliver the desired satisfaction more effectively and efficiently than competitors; customer or user experience is key

Table 3.1 STOF business model research framework (Bouwman et al. 2008)

\begin{tabular}{|c|c|}
\hline $\begin{array}{l}\text { Business model } \\
\text { domain }\end{array}$ & Description \\
\hline Service domain & $\begin{array}{l}\text { Delineates an organisation's service offering and the inherent value } \\
\text { propositions and the specific end-users in particular target customer } \\
\text { segments. }\end{array}$ \\
\hline $\begin{array}{l}\text { Technological } \\
\text { domain }\end{array}$ & $\begin{array}{l}\text { Describes the technical functions and core competencies needed to } \\
\text { realise the service offering. }\end{array}$ \\
\hline $\begin{array}{l}\text { Organisational } \\
\text { domain }\end{array}$ & $\begin{array}{l}\text { Defines how the organisation creates value from a service offering via } \\
\text { the configuration of actors (value network) comprising resources } \\
\text { which together perform value activities. }\end{array}$ \\
\hline Financial domain & $\begin{array}{l}\text { Conveys the revenue and cost structure arrangements operationalised } \\
\text { in order to capture value from a service offering. }\end{array}$ \\
\hline
\end{tabular}


(Bouwman et al. 2008). Functionality and technical architecture play pivotal roles in the technology domain. Functionality refers to the range of operations that can be performed by the service offering. The technical architecture relates to the "overall architecture of the components of a technical system in terms of backbone infrastructure, devices, service platforms, access networks and applications" (Bouwman et al. 2008, p. 115). The organisational domain revolves around the concept of a value network comprised of actors who possess "certain resources and capabilities, which interact and together perform value activities, to create value for customers and to realise their own strategies and goals" (Bouwman et al. 2008 , p. 116). Finally, the financial domain delineates how value is captured by various actors in a value network. This domain focuses on financial arrangements which "revolve around investment decisions, revenue models, and revenue sharing arrangements... [and] are aimed at average cost-effectiveness, net cash worth, and internal return" (Bouwman et al. 2008, p. 116).

The STOF framework is useful for a variety of reasons. First, it is relatively comprehensive, coherent and comprises business model components which are similar to other widely cited categorisations such as the business model canvas (Osterwalder and Pigneur 2010), the $\mathrm{V}^{4}$ business model ontology (Al-Debei and Fitzgerald 2010) and the integrated business model (Wirtz 2011). Second, the STOF framework typifies the business model elements contained within the concept matrix proposed recently by Peters et al. (2015). Third, it has been previously utilised to assess the impact of SaaS technologies on business models (Lee et al. 2014) although, it should be noted that these aforementioned studies have not focused on incumbent IT service providers. Finally, the STOF framework is dynamic in nature as it encapsulates external factors of influence in terms of market dynamics, technological advancements and regulatory changes that all represent salient factors in the context of provisioning SaaS technologies.

\subsection{Methodology}

A multi-method, comparative case study research design was selected for the study. Table 3.2 provides an overview of the primary data sources (i.e. respondent interviews) and the secondary data sources that were analysed as part of the case study. The two case firms selected for the study provide rich environments for investigating our research objective. They are large 
Table 3.2 Study data sources

Primary data sources (20 interviews)

\begin{tabular}{|c|c|c|c|}
\hline$I D$ & $\begin{array}{l}\text { Industry/size/business } \\
\text { model }\end{array}$ & Role & $\begin{array}{c}\text { Industry experience } \\
\text { (years) }\end{array}$ \\
\hline$A$ & \multicolumn{3}{|c|}{ Software/Large ITSP/Mature } \\
\hline $\mathrm{CAl}$ & & Senior SaaS Architect & 8 \\
\hline $\mathrm{CA} 2$ & & SaaS Strategy Leader & 9 \\
\hline CA3 & & SaaS Product Manager & 12 \\
\hline CA4 & & $\begin{array}{l}\text { Senior Cloud Infrastructure } \\
\text { Developer }\end{array}$ & 15 \\
\hline CA5 & & SaaS Leader & 11 \\
\hline CA6 & & SaaS Strategy Leader & 6 \\
\hline CA7 & & Chief Technology Officer & 9 \\
\hline CA8 & & SaaS Product Manager & 9 \\
\hline CA9 & & SaaS EMEA Leader & 11 \\
\hline$B$ & \multicolumn{3}{|c|}{ Software/large ITSP/mature } \\
\hline $\mathrm{CB} 1$ & & $\begin{array}{l}\text { Research \& Development } \\
\text { Director }\end{array}$ & 20 \\
\hline $\mathrm{CB} 2$ & & Senior SaaS Architect & 7 \\
\hline CB3 & & Senior SaaS Engineer & 19 \\
\hline $\mathrm{CB} 4$ & & EMEA SaaS Leader & 13 \\
\hline CB5 & & Cloud Datacenter Manager & 6 \\
\hline CB6 & & Senior SaaS Manager & 17 \\
\hline CB7 & & Senior SaaS Technologist & 14 \\
\hline CB8 & & Senior SaaS Engineer & 11 \\
\hline CB9 & & Senior SaaS Manager & 9 \\
\hline $\mathrm{CB} 10$ & & SaaS Development Manager & 12 \\
\hline CBll & & SaaS Product Manager & 18 \\
\hline
\end{tabular}

Secondary data sources

\begin{tabular}{|c|c|c|c|c|c|}
\hline $\begin{array}{l}\text { Websites, } \\
\text { white papers } \\
\text { and } \\
\text { marketing } \\
\text { materials }\end{array}$ & $\begin{array}{l}\text { Annual } \\
\text { and } \\
\text { quarterly } \\
\text { reports }\end{array}$ & $\begin{array}{l}\text { Company } \\
\text { presentations, } \\
\text { Blogs, YouTube, } \\
\text { Webinars and } \\
\text { Podcasts }\end{array}$ & $\begin{array}{l}\text { Industry } \\
\text { commentary } \\
\text { and analysis and } \\
\text { newspaper } \\
\text { articles }\end{array}$ & $\begin{array}{l}\text { Researcher's } \\
\text { field notes }\end{array}$ & $\begin{array}{l}\text { Reflective } \\
\text { memos }\end{array}$ \\
\hline
\end{tabular}

(>10,000 employees) multi-national incumbent IT service providers who have been at the forefront of the advancement and provision of SaaS technologies for the past six years. As such, both cases represent theoretical sampling (Glaser and Strauss 1967) and make it suitable for analytical generalisation (Yin 2003). Furthermore, developing insightful narratives 
for the digital age, calls, in part, for the selection of "compelling cases... [which are capable of producing]...powerful intellectual accounts" (Henfridsson 2014, p. 1). For company confidentiality, we pseudonymously refer to both case study companies as Case A and Case B. Following the standard practice of using senior management as data sources (Klein and Myers 1999; Flyvbjerg 2006; Iyer and Henderson 2012), we selected senior managers from each case organisation. A case study approach to analyse emergent complex field problems more than anything else, requires experience (Flyvbjerg 2006). As such, the interviewees were selected based on the following criteria: first, the respondents should have experience working with SaaS technology. Second, the respondents should hold managerial positions (e.g. SaaS product manager, chief technology officer, etc.), which would enable them to have an in-depth knowledge of the business model intricacies of their SaaS operations. Third, the respondents should preferably have responsibility for overseeing their organisation's business model activities. Table 3.2 provides an overview of the 20 respondent's cloud roles and their number of years' IT industry experience.

\subsection{Discussion of Findings}

Prior to provisioning SaaS technologies, both Case A and Case B core business activities encompassed the manufacturing and distribution of enterprise servers, storage devices and a diverse range of computational software. These companies have an illustrious heritage pertaining to their ability to innovate their business models in order to leverage nascent technological advancements. Since 2015 , both companies have prioritised the realignment and restructuring of their traditional IT business activities to focus solely on the provisioning of best of breed SaaS IT services. Therefore, both case organisations have experienced substantial success in the market. Table 3.3 provides a summary of the six tangible payoffs identified from the data analysis along the core business model domains. These payoffs can be categorised as being economic, business and transformative.

In terms of the service business model domain payoffs, the findings reveal that SaaS facilitates the provision of new products and services and enables an extended market reach. Concerning the former transformative benefit, the analysis revealed that SaaS has facilitated (1) the provision of virtualised SaaS-based solutions from a centralised location which possess the capability to automatically scale-up and down dynamically based on the 
Table 3.3 Tangible business model payoffs from provisioning SaaS

\begin{tabular}{|c|c|}
\hline Business model payoff & Empirical evidence from our study \\
\hline $\begin{array}{l}\text { Service domain: } \\
\text { Provision of New } \\
\text { Products and Services } \\
\text { (Transformative) }\end{array}$ & $\begin{array}{l}\text { SaaS enables both case organisations to create new and } \\
\text { innovative business ventures beyond their existing traditional } \\
\text { hardware and software services. The five essential characteristics } \\
\text { (e.g. on demand self-service, measured service etc.) which } \\
\text { underpin the SaaS model enables the case organisations to } \\
\text { deliver nuanced and customisable value propositions to the } \\
\text { customer. }\end{array}$ \\
\hline Service domain: & SaaS has enabled both organisations to penetrate new \\
\hline $\begin{array}{l}\text { Extended Market Reach } \\
\text { (Business) }\end{array}$ & $\begin{array}{l}\text { horizontal and vertical market segments. The case organisations } \\
\text { have established new growth strategies (e.g. new SaaS leader's } \\
\text { roles, SaaS marketing teams, digital ecosystems) within these } \\
\text { new segments in order to further establish their presence. }\end{array}$ \\
\hline $\begin{array}{l}\text { Technological Domain: } \\
\text { Fast Software } \\
\text { Development, } \\
\text { Deployment and } \\
\text { Maintenance } \\
\text { (Transformative) }\end{array}$ & $\begin{array}{l}\text { Centralised data centres and advancements in automation and } \\
\text { scalability have transformed the manner with which both case } \\
\text { organisations develop, deploy and maintain IT services. This } \\
\text { transformation has enabled the case organisations to change } \\
\text { the polarity of how they conduct business with customers. }\end{array}$ \\
\hline $\begin{array}{l}\text { Organisational Domain: } \\
\text { Enhanced Agility } \\
\text { (Business) }\end{array}$ & $\begin{array}{l}\text { Both case organisations are pivoting rapidly towards agile } \\
\text { methodologies in order to effectively create value from } \\
\text { provisioning SaaS technologies. Both companies have } \\
\text { experienced enhanced business agility as a result of their large } \\
\text { scale internal restructuring of their existing departments, } \\
\text { teams, developmental practices and collaborative tools in line } \\
\text { with their SaaS developmental strategies. }\end{array}$ \\
\hline $\begin{array}{l}\text { Organisational Domain: } \\
\text { Expanded Value } \\
\text { Network } \\
\text { (Transformative) }\end{array}$ & $\begin{array}{l}\text { The results revealed that in order to step in line with the } \\
\text { orientation of the SaaS market towards hybrid, open, and } \\
\text { interoperable SaaS services both case organisations have had to } \\
\text { carry out substantial restructuring of their traditional static and } \\
\text { rigid value networks. These new SaaS value networks comprise } \\
\text { a multitude of new actors and practices. }\end{array}$ \\
\hline $\begin{array}{l}\text { Financial Domain: } \\
\text { Reduced Operating } \\
\text { Costs (Economic) }\end{array}$ & $\begin{array}{l}\text { SaaS has enabled the case organisations to significantly reduce } \\
\text { their operating costs in comparison to the traditional mode of } \\
\text { operation. The ability to centralise their provisioning } \\
\text { operations from key global locations was identified as a key } \\
\text { contributor to this reduced cost. The subsequent savings are } \\
\text { being reinvested by both organisations into new technological } \\
\text { strategic priorities. }\end{array}$ \\
\hline
\end{tabular}


demand for computational resources and (2) the creation of new and innovative products which have subsequently led to new spin-off services. The advantages derived from these new products and services (e.g. new revenue streams, reduced development times frames and budgets) would not have been feasible without SaaS. For example, senior managers from Case A discussed how SaaS has enabled the company to create a suite of new products and services. For example, they all pointed to one of their most successful products which is currently receiving global recognition for its cognitive capacity. The new system, which encompasses state of the art real time big data analytics functionality, is currently being used extensively in medical, pharmaceutical and biotechnology industry sectors. A senior manager described how the product was also being used at global sporting events:

We are using the SaaS system to help us monitor major sporting events in terms of internet traffic, social analytics, and sentiment analysis. Based on these metrics the cognitive system can compute whether or not these factors will cause a spike in the usage of the customer services (e.g. website, booking systems etc.). The system then automates additional headroom on the capacity to cater for this spike without any human intervention. (CA5)

The informants confirmed that without SaaS technology, this product's core value propositions would be not as attractive for the customer. As one senior manager remarked:

SaaS has enabled us to create a virtualised product which is $80 \%$ smaller, roughly 20 times faster and possesses exponentially more functionality in comparison to if we had attempted to design it with traditional methods. This product has been the catalyst for new spin-off cloud and Big Data services. (CA9)

In terms of the extended market reach benefit, the study revealed that SaaS enabled both organisations to enhance services to existing market segments while concurrently penetrating both new horizontal and vertical market segments. The case informants described how high costs, long project implementation periods and rigid partner networks encompassed within their traditional business models represented salient barriers to expanding their market reach. However, the findings identified that SaaS all but eradicated these barriers and enabled both organisations to not only provision SaaS services directly from their indigenous website and 
digital ecosystem portals but also configure new virtual value networks in order to access new customers across diverse industry segments. Individual customers and small and medium enterprises represent new market segments which both case organisations are attempting to establish a strong presence. In order to effectively leverage the extended market reach business benefit, both companies have established new growth strategies (e.g. new SaaS leader roles, SaaS marketing teams, digital ecosystems) within these new market segments.

Senior Managers from Case A and Case B provided the following insights:

SaaS technology has enabled us to provide our offerings to a broader market in comparison to our traditional mode of operation. Traditionally, numerous business partners along the value network would supply and install our products. We can now provision these same offerings rapidly from a centralised location which has dramatically reduced our costs. (CBII)

SaaS has opened up new markets in terms of acquiring new customers who are interested in solely SaaS based solution and also providing SaaS services to our existing customer base. With our particular SaaS products, we are able to distribute it to multiple customers in a multi-tenant environment. Should our customer base grow we can automatically provision new servers and create working environments for them within an hour. (CA4)

In terms of the transformative technological business model domain benefit of fast software development, deployment and maintenance, this study identified how centralised data centres and advancements in automation and scalability have transformed the manner with which both case organisations develop, deploy and maintain IT services. This transformation enabled the case organisations to change the polarity of how they conduct business with customers. SaaS enables IT service providers to consolidate multiple customers into a single centralised data centre location that is managed by a core group of employees. SaaS also significantly transformed both case organisation's automation capabilities by enabling them to roll out products, services and features rapidly. This capability is extremely important given the variances in customer requirements which might require frequent changes to SaaS solutions. The case organisations can now upgrade their SaaS offerings to their latest versions seamlessly from a centralised location. In some instances, this process can occur without any human intervention. In the traditional model, the case organisation's IT 
products/infrastructure would have been dispersed globally which would have incurred substantial time and cost constraints. The following insights by senior managers from Case A and Case B sums up nicely the service transformation that is taking place in both organisations from a technological domain point of view:

It is not traditional IT any more. It is all about fast repurposing. In the traditional IT model, if a machine went down, it could take a couple of days or even weeks to repair. Now in a SaaS computing context if a virtual machine goes down another one can be quickly spun up in its place. You can just nuke the old machine and create a new one. There is flexibility and scalability from a provider's point of view to accommodate the multifarious needs of our customers in real time 24/7/365. Our CPU cycles are being repurposed constantly. (CB7)

In our traditional model, we were limited by the tight time frames with which we would have had to adhere to in order to develop and deploy a particular product. There would have been absolutely no lee way given what so ever. The final product delivered which was delivered was oftentimes substandard which would subsequently have led to a lot of negative press. If we had used SaaS for similar projects, we would have been able to develop and release the products far more rapidly leading to a greater product success. (CA3)

Enhanced agility and an expanded value network were identified as the two keys organisational business model domain payoffs derived from operationalising SaaS-enabled business models. With regards to the former business benefit, both case organisations are currently undergoing large scale internal and external SaaS transformation. Their long-term objective is to provide the majority of their portfolios of capabilities in SaaS service models formats (e.g. high-end consulting, technical services, business processes, software and so on). The companies are also carrying out an internal restructuring of all of their existing teams, developmental practices and collaborative tools in line with their SaaS developmental strategies. This transformation not only resulted in cost savings but also enabled both case organisations to enhance their business agility. The findings revealed that it was a deliberate strategy for both organisations to address the serious agility gaps which were curtailing their abilities to respond effectively to a rapidly changing technological landscape. At that time both organisations existing levels of business agility were ineffectual at coping with the nuances inherent to provisioning SaaS technologies. Thus, strategic developments were prioritised and set in motion in order to address these 
agility gaps. This enhanced agility not only enabled both case organisations to deal effectively with a continually evolving and increasingly uncertain technological landscape, but also resulted in improved internal collaboration practices within both organisations. Senior managers from Case $\mathrm{A}$ and Case B provided the following insights:

The company as a whole have readily embraced the SaaS movement. In the last five years, Saas has become pervasive across all of our business units. Traditionally we were seen as being the equivalent of a large cargo boat of the IT world. It wasn't sexy but we got the job done. We were a safe choice. However, with SaaS the customer does not want the large freight, they want us to be a racing yacht encompassing the same level of robustness, but they want that service for the price of a renting a row boat. That is why everything we do has to be SaaS native. (CA8)

SaaS has completely changed the paradigm of how we do business whereby it has significantly enhanced our agility. We are not only responding to customer needs and suppliers faster but are also able to react to competitors more effectively. We are also using our agile war experiences in order to help our customers maximise SaaS enabled agility within their organisations. (CB6)

With regards to the transformative expanded value network benefit, these value networks are paramount for creating value with SaaS. For example, SaaS facilitated both case organisations to create new flexible virtual value networks in order to shape attractive value propositions and revenue streams which would not be feasible for both organisations on their own. As a senior manager from Case A remarked:

SaaS has encouraged us to reimagine what our traditional value network, which was largely rigid and closed off to a small number of business partners, would look like on a virtual plain which is open, ubiquitous, flexible and contains thousands of actors. (CA3)

Both case organisations have recently developed indigenous OpenStack collaborating network platforms which enables service providers, independent developers, resellers, integrators and telecommunications companies to resell both case organisation's SaaS products and services. These newly formed partnering programs enable them to enhance their ability to target customers on a global scale who favour open source, interoperable and hardware agnostic SaaS services. The informants also reported that 
customers are increasingly playing a more prominent role within their SaaS value networks. This is enabling both case organisations to create best of breed SaaS products and solutions and bring them to market faster. Both case organisations provide customers with open tools and services in order to transform their standardised products to align with the multifarious nature of customer requirements. The participants also revealed that their organisations hold regular networking events at which customers can give them face-to-face feedback on their services. Both case organisations have also simplified the process with which business partners along the value network can demo their SaaS solutions to customers.

The final SaaS-enabled business model benefit relates to the financial domain whereby provisioning SaaS technologies facilitated reduced operating costs. This economic benefit manifested in the significant reduction of their operating costs in comparison to their traditional mode of operation. SaaS enabled the centralisation of provisioning operations from key global locations (e.g. management of SaaS services in terms of monitoring and providing service upgrades). This is in comparison to the traditional mode of operation which encompassed the running of small silos of compute across both organisations, which were maintained by different teams. This ability to centralise costs while simultaneously achieving an increase in customer volume was identified as a key contributor to this reduced cost. The analysis also revealed that the costs pertaining to customer relationship management were also significantly impacted. First, SaaS significantly reduced both firm's costs pertaining to acquiring new customers. The flexibility inherent to the SaaS-enabled economic models, whereby customers can now trial or purchase SaaS solutions via credit card, purchasing order, or finance methods, has been revolutionary for both companies. The whole process is seamless in comparison to the traditional model. Second, provisioning SaaS technology significantly lowered both companies' administrative overheads pertaining to how they manage and support customers. Both organisations provide their customers with the ability to independently configure and manage SaaS services (e.g. OpenStack). Selfsupport facilities are also provided to enhance the simplicity and ease of use.

Senior managers from Case A and Case B also commented on the economies of scale which were being derived from provisioning centralised SaaS services:

From the company's point of view, it is far more cost effective for us to operationalise one data centre which manages a thousand customers rather than having 
to partner on a thousand different solutions and assigning those with individual organisational staff. So, collapsing a totality of needs into one centralised data centre manifests in cost efficiencies in service development, management, distribution and resourcing. (CA7)

Over time we envisage more and more compute resources being concentrated in fewer but larger data centres. The cost of making hardware and servers, in the traditional model, which could be used and serviced safely by a regular user was quite high. Now these are being aggregated in large scale data centres. The company are optimising for very large data centres where we have complete control from a centralised location. (CBI)

The case study analysis also revealed that the cost savings derived from provisioning SaaS services are being reinvested into developing new skillsets and new strategic technological priorities and growth areas such as Big Data, security, analytics and mobility.

\subsection{Conclusion}

Using an in-depth case study approach incorporating two incumbent IT service providers, this study reveals six tangible payoffs which have manifested across their core business model's domains. These payoffs are categorised as being economic, business and transformative. We now enumerate the implications of the following study. First, we used the STOF business model framework as an analytical anchor in order to present a general understanding of the transformative, beneficial and constraining impacts of SaaS-based digital transformation on incumbent IT service providers. Such IT-based business model insights, "prepare the path for significant contributions in understanding underlying mechanisms of business model success and failure" (Veit et al. 2014, p. 50) in an increasingly digitised enterprise world. Moreover, this research provides much needed insights into how SaaS-based digital transformation changes entire business models (Benlian et al. 2016). Second, this study demonstrates that both case organisations are reaping top line (e.g. increased organisational agility, increased sales, enhanced technological capabilities), and bottom line (e.g. reduced operational costs, improved customer experience and satisfaction) payoffs. Thus, this study can serve as a baseline for entrenched incumbent IT service providers to juxtapose and weigh up the transformative, business and economic payoffs that can be derived from provisioning SaaS technologies. It was interesting to note that both case 
organisations also experienced specific constraints (organisational and SaaS technology level) which inhibited both case organisations' ability to effectively leverage the payoffs of SaaS-based business models. Future research could investigate how IT service providers develop workarounds in order to overcome these constraints. Additionally, our study specifically focused on incumbent IT service providers. Future studies could broaden this scope and investigate how SaaS impacts the business models of IT service providers who were 'born on the cloud'. It is also interesting to further examine the difference between those IT services providers who failed to successfully leverage the business value of SaaS technologies versus those who did reap the rewards. Finally, other creditable business model frameworks such as the business model canvas may also provide additional insights and deserve further exploration as well.

\section{REFERENCES}

Al-Debei, M. M., \& Fitzgerald, G. (2010, March). The Design and Engineering of Mobile Data Services: Developing an Ontology Based on Business Model Thinking. In IFIP Working Conference on Human Benefit through the Diffusion of Information Systems Design Science Research, 28-51. Berlin, Heidelberg: Springer.

Benlian, Alexander, W. Kettinger, Ali Sunyaev, and T. Winkler. 2016. The Transformative Value of Cloud Computing. Journal of Management Information Systems 35: 719-739.

Bouwman, Harry, Edward Faber, Timber Haaker, Björn Kijl, and Mark De Reuver. 2008. Conceptualizing the STOF Model. In Mobile Service Innovation and Business Models, 31-70. Berlin, Heidelberg: Springer.

Clohessy, Trevor, Thomas Acton, and Lorraine Morgan. 2017. The Impact of Cloud-based Digital Transformation on IT Service Providers: Evidence from Focus Groups. International Journal of Cloud Applications and Computing (IJCAC) 7 (4): 1-19.

Díaz-Díaz, Raimundo, Luis Muñoz, and Daniel Pérez-González. 2017. Business Model Analysis of Public Services Operating in the Smart City Ecosystem: The Case of SmartSantander. Future Generation Computer Systems 76: 198-214.

Flyvbjerg, Bent. 2006. Five Misunderstandings about Case-Study Research. Qualitative Inquiry 12 (2): 219-245.

Gartner. 2018. Gartner Forecasts Worldwide Public Cloud Revenue to Grow 21.4 Percent in 2018. Accessed l February 2018. https://www.gartner.com/news$\mathrm{room} / \mathrm{id} / 3871416$.

Glaser, Barney G., and Anselm L. Strauss. 1967. The Discovery of Grounded Theory: Strategies for Qualitative Theory. New Brunswick, NJ: Aldine Transaction. 
Guo, Zhiling, and Dan Ma. 2018. A Model of Competition between Perpetual Software and Software as a Service. MIS Quarterly 42 (1): 1.

Henfridsson, Ola. 2014. The Power of an Intellectual Account: Developing Stories of the Digital Age. Journal of Information Technology 29: 356-357.

Hess, Thomas, Christian Matt, Alexander Benlian, and Florian Wiesböck. 2016. Options for Formulating a Digital Transformation Strategy. MIS Quarterly Executive 15 (2): 6.

Iyer, Bala, and John C. Henderson. 2012. Business Value from Clouds: Learning from Users. MIS Quarterly Executive 11 (1): 51.

Klein, Heinz K., and Michael D. Myers. 1999. A Set of Principles for Conducting and Evaluating Interpretive Field Studies in Information Systems. MIS Quarterly 23: 67-93.

Lee, Y. Y., Noridah, N., Hassan, S. A. A. S., \& Menon, J. (2014). Absence of Helicobacter Pylori is not Protective Against Peptic Ulcer Bleeding in Elderly on Offending Agents: Lessons from an Exceptionally Low Prevalence Population. PeerJ, 2, e257.

Osterwalder, A. and Pigneur, Y., 2010. Business Model Generation: A Handbook for Visionaries. Game Changers, and Challengers. John Wiley \& Sons.

Peters, Christoph, Ivo Blohm, and Jan Marco Leimeister. 2015. Anatomy of Successful Business Models for Complex Services: Insights from the Telemedicine Field. Journa lof Management Information Systems 32 (3): 75-104.

Van Kerkhoff, L. (2014). Developing Integrative Research for Sustainability Science through a Complexity Principles-based Approach. Sustainability Science 9: 143-155.

Veit, Daniel, Eric Clemons, Alexander Benlian, Peter Buxmann, Thomas Hess, Dennis Kundisch, Jan Marco Leimeister, Peter Loos, and Martin Spann. 2014. Business Models. Business \& Information Systems Engineering 6 (1): 45-53.

Wirtz, H. (2011). Innovation Networks in Logistics-management and Competitive Advantages. International Journal of Innovation Science, 3(4): 177-192.

Wirtz, B. W., Pistoia, A., Ullrich, S., \& Göttel, V. (2016). Business models: Origin, Development and Future Research Perspectives. Long Range Planning, 49(1): 36-54.

Yin, Robert K. 2003. Case Study Research Design and Methods, Applied Social Research Methods Series 5. 3rd ed. SAGE. 
Open Access This chapter is licensed under the terms of the Creative Commons Attribution 4.0 International License (http://creativecommons.org/licenses/ by $/ 4.0 /$ ), which permits use, sharing, adaptation, distribution and reproduction in any medium or format, as long as you give appropriate credit to the original author(s) and the source, provide a link to the Creative Commons licence and indicate if changes were made.

The images or other third party material in this chapter are included in the chapter's Creative Commons licence, unless indicated otherwise in a credit line to the material. If material is not included in the chapter's Creative Commons licence and your intended use is not permitted by statutory regulation or exceeds the permitted use, you will need to obtain permission directly from the copyright holder. 